\title{
Management of Zygomatico maxillary complex fractures with two-point fixation-A retrospective study for 5 years
}

\author{
Devakumari Shanmugam1, Vijhayapriya Thanasekaran², Nandini Biradar ${ }^{3}$, \\ Amudha Purushothaman ${ }^{4}$, Dinesh Sridhar ${ }^{5}$, Devameena Shanmugam ${ }^{6}$ \\ ${ }^{1}$ Associate Professor, Department of Dentistry, Indira Gandhi Medical College and Research Institute (Govt.), \\ Puducherry, India, ${ }^{2}$ Associate Professor, ${ }^{4}$ Assistant Professor, Department of Ophthalmology, Indira Gandhi Medical \\ College and Research Institute (Govt.), Puducherry, India, ${ }^{3}$ Associate Professor, Department of Dentistry, Bidar \\ Institute of Medical Sciences, Bidar, Karnataka. India, ${ }^{5}$ Professor and Head, Department of Conservative Dentistry and \\ Endodontics, ${ }^{6}$ Senior lecturer, Department of Prosthodontics and Crown and Bridge, Sri Venkateswara Dental College \\ and Hospital, Ariyur, Puducherry, India
}

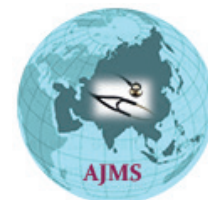

\section{A B STR A C T}

Background: The Zygomatico maxillary complex fractures (ZMC) are commonly encountered in the practice of the maxillofacial surgeon. Perfect management of the fracture is absolutely essential as the revision surgeries are tedious. Surgical management of ZMC is done at two or three points depending on the clinical displacement. Aims and Objectives: Zygomatico maxillary complex is the second most common fractures next to nasal bone fracture in the face worldwide. ZMC fractures are frequently seen and they were managed in great volumes throughout the country. The aim of our study is to prove the surgical outcomes of two-point fixation in the management of ZMC fractures. Materials and Methods: The inpatient records follow up records, radiographic records and photographs of 55 patients who underwent management of ZMC with two point fixations (one at zygomatic buttress and one at the fronto zygomatic region) were retrieved and analysed for the surgical outcomes. The evaluation was done preoperatively and postoperatively at 4 weeks, 8 weeks and 12 weeks. Result: Two-point fixations give stable results both aesthetically and functionally in the management of Zygomatico maxillary complex fractures. Conclusion: Rigid internal fixation with titanium miniplates at two points in zygomatic buttress and in the fronto zygomatic region can be adopted with confidence as it gives excellent results. The scar formed in the infraorbital region or the unsightly ectropion can be avoided by not including the infra orbital region.

Key words: Zygomatico maxillary complex; Fractures; Zygoma; Internal fixation
http://nepjol.info/index.php/AJMS DOI: 10.3126/ajms.v12i1.31114

E-ISSN: 2091-0576

P-ISSN: 2467-9100

Copyright (c) 2021 Asian Journal of Medical Sciences

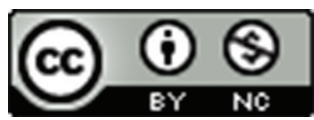

This work is licensed under a Creative Commons Attribution-NonCommercial 4.0 International License.

\section{INTRODUCTION}

The Zygomatico maxillary complex fractures are commonly encountered in the practice of the maxillofacial surgeon. $\mathrm{ZMC}$ is vulnerable to fracture because it is prominent next to nasal bone prominence. Various studies from India and worldwide on the etiology of the fracture of ZMC and Zygomatic arch recorded that RTA, inter personal assault, self-fall and sports injuries as the contributing factors. A medially displaced fracture hinders with the movement of the mandible and leads to trismus. A laterally or inferiorly or posterior displaced ZMC leads to enophthalmous/ vertical dystopia due to increase in orbital volume. Further, correction of these facial fractures at the earliest is indicated to overcome these functional deformities. The additional clinical entity which few patients experience is the neurapraxia of the Infra orbital $\mathrm{N}$ due to the impingement of fracture fragments. A planned and timely intervention is absolutely essential as the revision surgeries in the facial region is a herculean task. Moreover the outcome of the revision surgeries with respect to restoration of aesthetics and function is suboptimal when compared to 
surgeries done within two weeks of the injury. So, surgical intervention, open reduction and internal fixation of ZMC are the accepted treatment worldwide for the last two decades. Management of ZMC fractures are done in great volumes in the Indian subcontinent due to increased incidence of RTA. Consensus regarding the fixation of the ZMC fractures in two points or three points still remains controversial. This study, which was done in a tertiary care hospital, in south India gives the insight about two-point fixations in the management of ZMC fractures.

\section{MATERIALS AND METHODS}

Fifty-five patients of ZMC fractures who underwent ORIF (Two-point fixation) under GA were included in the study. The study was done after obtaining institute ethics committee clearance (No163/IEC/IGMC\& RI /F7/2018.)

\section{Inclusion criteria}

1. Patient who reported within $72 \mathrm{hrs}$ of injury.

2. Age group -19 to $60 \mathrm{yrs}$

3. Fractures operated within 10 days of injury

4. Isolated ZMC fractures

5. Patients with or without parasethesia of infra orbital $\mathrm{N}$

6. Clinical presentation of Enophthalmous/vertical dystopia

7. Trismus

8. Malar height disproportion to contra lateral side

9. Associated undisplaced/mildly displaced zygomatic arch fractures

\section{Exclusion criteria}

Associated fractures such as

1. Communitted Zygomatic arch fractures

2. Mandibular fractures

3. Lefort fractures

4. Bilateral ZMC fractures

5. Patients already treated for facial fractures

6. Patients with orbital floor fractures

The parameters that were assessed were Demographics, etiology, clinical parameters like trismus, vertical dystopia, correction of malar asymmetry and enophthalmous. The inpatient records and follow up records of the patients were analyzed in the study (at 4 weeks, 8 weeks and 12 weeks). Patient's radiographs, photographs and CT scans were analysed to evaluate the surgical outcomes of two point fixation for ZMC fractures.

\section{Surgical procedure}

Elevation through intra oral Keens' approach was done after a vestibular incision. Next the zygomatic buttress was exposed followed by lateral eyebrow incision
(Schematic diagram 1). The first fixation was done in fronto zygomatic region followed by the zygomatic buttress (Schematic diagram 2). This sequential manner of two-point fixation (Figures 1-4) gives three-dimensional stability. Fixation in Fronto zygomatic region after elevation through Keens' approach gives one more chance to reduce the fracture and fix the fracture. This is due to the fact that the fractures were clearly visible for manipulation in lateral eyebrow approach. Fixing in fronto zygomatic region retains the displaced bone in place, aids in fixation of the next point. The second point was zygomatic buttress, this provides the stable fixation as it counteracts with the pull of masseter. Further, fixation in the fronto zygomatic vertical buttress gives a stable fixation against the rotational forces. All the patients were instructed not to sleep in the operated side to avoid displacement and advised to take soft diet to avoid the pull of masseter in zygomatic buttress. Moreover, the staple food of south India is Rice and Rice products and this does not produce much masticatory pull over the

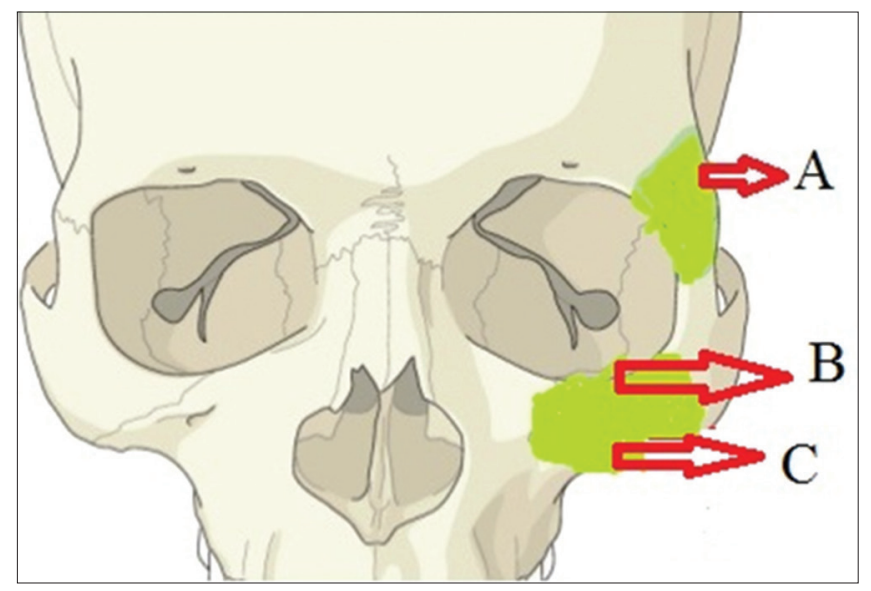

Schematic Diagram 1: (A) Fracture of frontozygomatic region, (B) Fractrure of infraorbital margin, (C) Fracture of zygomatic buttress

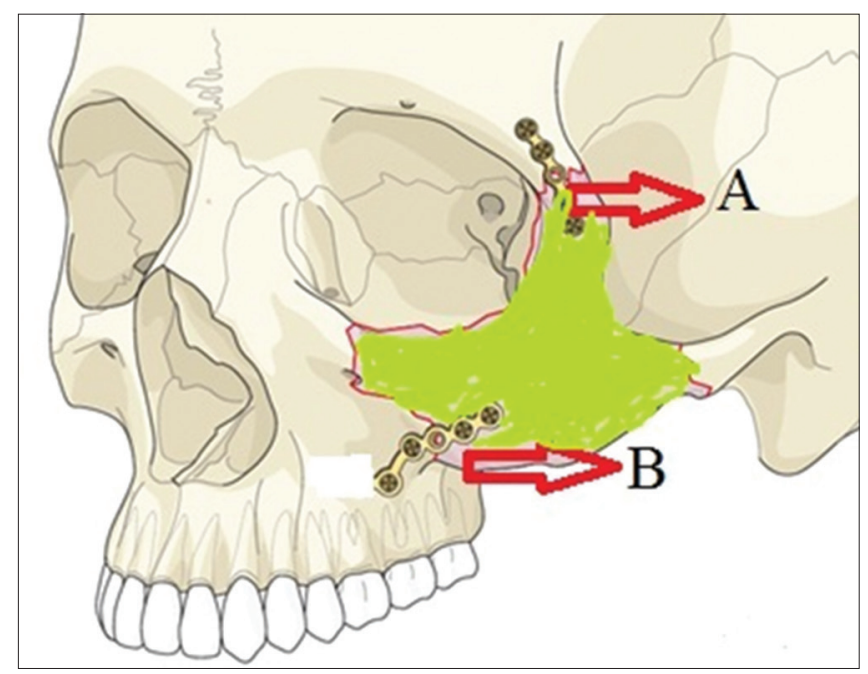

Schematic Diagram 2: (A) Miniplate fixation in the frontozygomatic region, (B) Miniplate fixation in the zygomatic buttress 


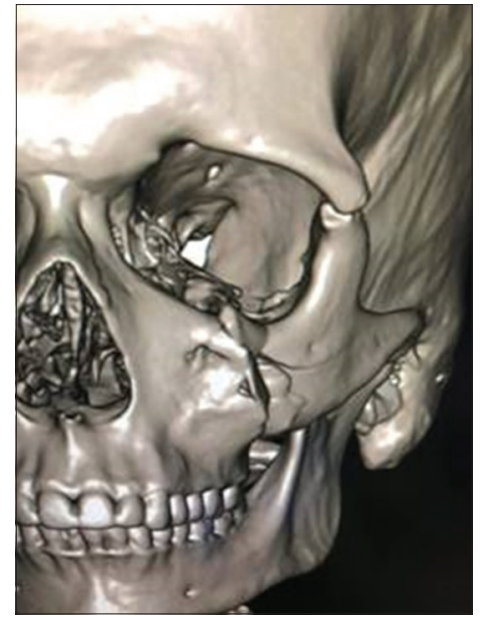

Figure 1: Pre operative CT Scan

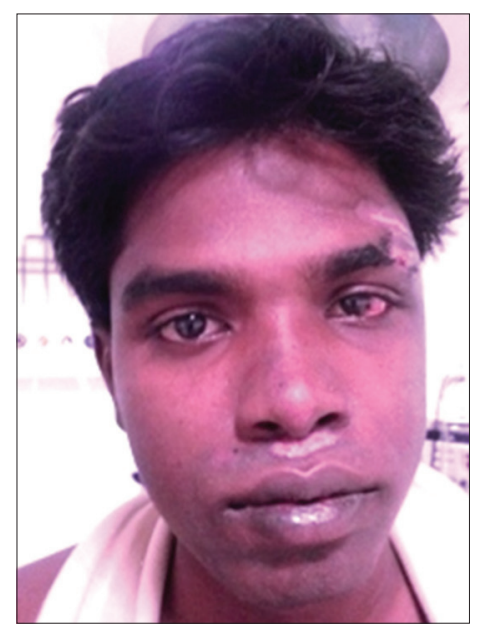

Figure 2: Pre operative photo with enophthalmous and malar flattening

fixed fractured sites. The ORIF under GA were done by a single operating surgeon for all the patients included in the study. Informed consent for surgery plus the permission to publish patient's photographs and their clinical reports were obtained from all patients who underwent surgery under general anaesthesia for the management of maxillofacial fractures.

\section{RESULT}

On analysis of the patient's data, it is evident that fractures of ZMC occur most commonly in males than females (Graph 1). RTA is the most common etiology followed by assault, sports injury and fall from height (Graph 2). On analysis of the clinical parameters (Table 1) it is evident that none of the patient had trismus. Vertical dystopia was present in two of the patient on clinical examination at fourth week. Although this is evident clinically and radiologically none of patients had complained on follow up since it was mild. One of the patients had persistent

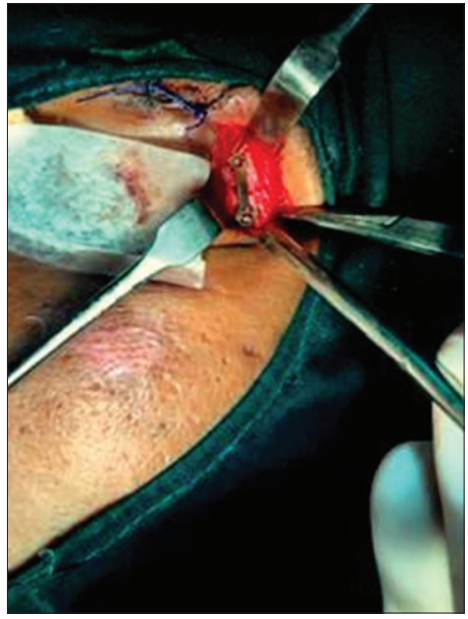

Figure 3: Fixation of fronto zygomatic fracture with miniplates

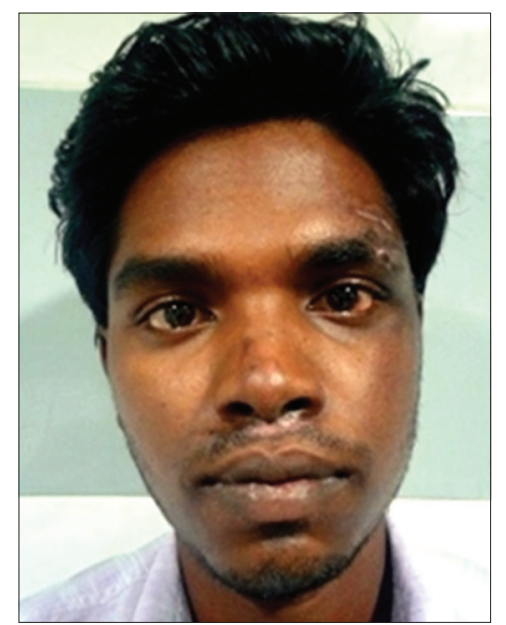

Figure 4: Post operative -malar asymmetry and Enophthalmous corrected

\begin{tabular}{lcccc} 
Table 1: Follow up for $\mathbf{1 2}$ weeks \\
\hline & $\begin{array}{c}\text { Trismus } \\
\mathbf{N}=\mathbf{5 5}\end{array}$ & $\begin{array}{c}\text { Vertical } \\
\text { dystopia } \\
\mathbf{N}=\mathbf{5 5}\end{array}$ & $\begin{array}{c}\text { Enophthalmous } \\
\mathbf{N}=\mathbf{5 5}\end{array}$ & $\begin{array}{c}\text { Malar } \\
\text { asymmetry } \\
\mathbf{N}=\mathbf{5 5}\end{array}$ \\
\hline 4 weeks & 0 & 2 & 1 & 3 \\
8 weeks & 0 & 2 & 1 & 2 \\
12 weeks & 0 & 2 & 1 & 2 \\
\hline
\end{tabular}

enophthalmous at the end of fourth week as this patient had a laterally displaced fracture with increased orbital volume. Malar asymmetry was seen in 3 patients at fourth week but at the end of eighth and twelfth week it was evident in 2 patients only. This can be attributed to mild persistent facial swelling in severely displaced fractures.

\section{DISCUSSION}

Zygoma is a strong cheek bone with four articulations. The buttresses of the face that are connected to ZMC are naso maxillary in the anterior aspect, the pterygomaxillary 


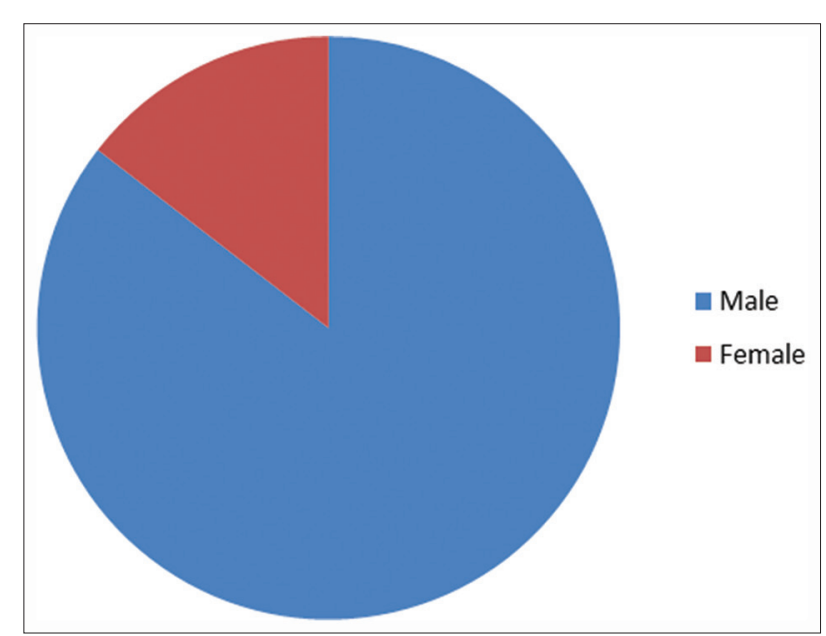

Graph 1: Gender Distribution

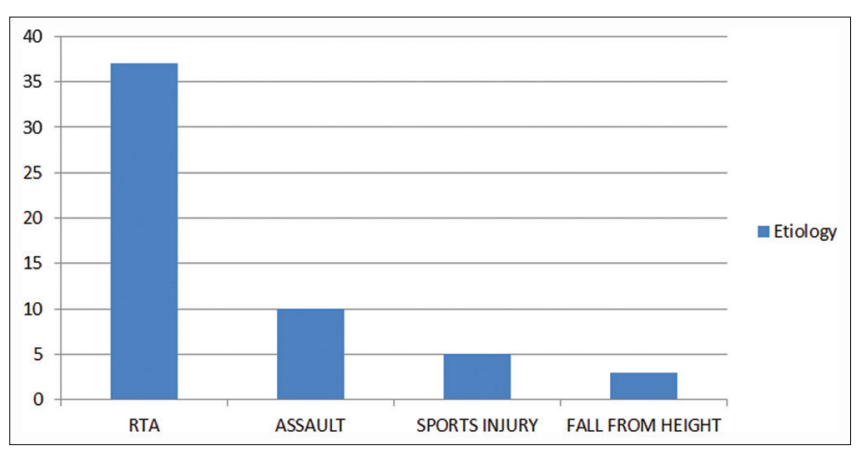

Graph 2: Etiology Of Zygomatic Fractures

in posterior aspect and laterally the Zygomatico maxillary buttress. Commonly, an injury to the face leads to disarticulation of the suture lines rather than the fracture of the zygoma proper. ${ }^{1}$ The most common etiology of ZMC fractures are $\mathrm{RTA}^{2}$.ZMC fractures are seen in isolation or in combination of other midface fractures due to complex mid face anatomy. ${ }^{3-5} \mathrm{ZMC}$ causes ocular and functional deformities, so this makes the surgical treatment mandatory. ${ }^{6}$ Studies by Zing ${ }^{7}$ and Covington ${ }^{8}$ proves that $90 \%$ Zygomatic fractures are treated by open reduction. Dingman and Natvig demonstrated that most fractures treated by closed reduction lead to severe injuries than their pre operative status and the study was in favour of open reduction for displaced fractures. ${ }^{9}$

It is claimed that alignment of spheno Zygomatic junction is the key for reduction in laterally displaced fractures. This sequential approach had led to the preservation of facial width and the height. ${ }^{10} \mathrm{~A}$ closed reduction of a displaced fracture leads to persistent diplopia, malunion and residual deformity of the face. ${ }^{11}$ Closed reduction techniques are reserved for only fractures with mild displacement. Keens intraoral approach was used in all our cases before fixation and it is an excellent approach for ZMC reduction without a cutaneous scar. De Souza et al used Keens approach with its modification to fix the infra orbital rim ${ }^{12}$. Management of ZMC fractures in one point, two point or three point still remains a controversy. The undisplaced, non communited fracture of lateral orbital rim or infra orbital rim can be managed by one-point fixation in the maxillary buttress. ${ }^{13}$ Kim et al used one-point fixation in zygomatic buttress without addressing fronto zygomatic or infraorbital region. He claimed that the method is aesthetically satisfactory and found no difference in stability. ${ }^{14} \mathrm{O}$ Hara proved that maxillary buttress fixation is the best fixation site as it counteracts the pull of masseter and gives an aesthetically acceptable scar as it is present under the muscle and he added that the infra orbital region is the least preferred site. ${ }^{15}$ Nitsh A et al used two point fixations in which he fixed the zygomatic buttress as the first point and the second point is either Infra orbital rim or the fronto zygomatic region in two study groups. They strongly suggested that zygomatic buttress should be fixed and fronto zygomatic or infra orbital rim can be alternated. The study concluded that three-point fixation is only for laterally displaced fractures. ${ }^{16}$ According to Ellis et al maxillary vestibular approach was used commonly with either infra orbital rim or the fronto zygomatic fixation. They also ascertained that complication with vestibular approach is less and with other two approaches it increases by $20 \%{ }^{17}$ Nagossa $\mathrm{M}$ et al in his computer assisted study on the stress levels at bone screw interface claimed that maximum stress is at the infra orbital rim. ${ }^{18}$

Parashar et al on his study says that single fixation fails to address three-dimensional stability as it does not counteract with the rotational forces. Further, he claimed that threepoint fixation leads to unsightly scar and nerve palsy ${ }^{19}$. Gandhi et al proved that stability with two-point fixation is as good as three-point fixation when miniplates were used. ${ }^{20}$ Choung and Kaban used lateral eyebrow as the initial approach because of direct access, imperceptible scar and no complications. ${ }^{21}$

Nishta and Gadkari in their systematic review proved that 5 out 8 studies support three point fixation. ${ }^{22} \mathrm{Na}$ and Lim et al had found no difference in stability between two point and three point fixation however he found difference in the facial projection. ${ }^{23}$ Wail et al compared two and three point fixation in two groups and evaluated surgical outcomes with CT scans. He found no significant difference in stability and concluded that two-point fixation is as good as three-point fixation with respect to stability of fractures. ${ }^{24}$ Sarkarat et $\mathrm{a}^{25}$ studied the stress, strain and rotational forces after one-point fixation in ZMC fractures by finite element analysis and concluded that fixation of miniplate in $\mathrm{FZ}$ tolerates more masticatory force than infraorbital rim. Rana et a ${ }^{26}$ measured vertical dystopia and malar height discrepancy in two study groups who underwent two-point 
fixation and three-point fixation. Rana et al. recorded average malar height in two-point fixation being $66.72 \pm$ $3.62 \mathrm{~mm}$ with minimum and maximum value of $59 \mathrm{~mm}$ and $75 \mathrm{~mm}$, respectively, while average malar height in three-point fixation being $68.26 \pm 3.76 \mathrm{~mm}$ with minimum and maximum value of $60 \mathrm{~mm}$ and $74 \mathrm{~mm}$, respectively. Average vertical dystopia in two-point fixation was $3.18 \pm$ $1.003 \mathrm{~mm}$ with a range of $4 \mathrm{~mm}$ and in three-point fixation; average vertical dystopia was $2.36 \pm 1.102 \mathrm{~mm}$ with a range of $3 \mathrm{~mm}$. The values were statistically significant between two groups but the improvement in the vertical dystopia and malar height increase is only slightly greater with threepoint fixation than the two-point fixation.

A study on stability of two-point fixation was conducted by Mittal et $\mathrm{al}^{27}$ by measuring the pre and post operative values of vertical dystopia and malar height discrepancy. The study showed a statistically significant increase in clinical parameters post operatively and hence proves that two-point fixation leads to stable fixation of the fractured fragments.

Two-point fixations were routinely done in our centre for the past 7 years in the management of ZMC fractures (Figure 1-4). This protocol of two-point fixation is followed because numerous studies from India support the technique. Moreover, getting an informed consent for performing infra orbital approach for fixation was little difficult as the patients were not prepared for the unsightly scar below the eye. This is because most of the patients were young males. The commonest etiology is RTA due to the poor compliance to traffic rules. In RTA, out of 37 patients 26 patients were under the influence of alcohol during driving. Interestingly all the sports injury was because of cricket ball injury or injury while playing cricket. Fall from height happened only in construction workers.

On evaluation of clinical parameters, out of 55 patients 2 patients had vertical dystopia and one patient had enophthalmous. This is due to severe lateral and inferior displacement of the fracture fragment. Malar asymmetry was evident in 3 patients at the end of 4 weeks and reduced to 2 patients at the end of 8 weeks and 12 weeks. This is due to persistent mild swelling on the management of severely displaced fractures.

Our institutional experience and results clearly demonstrated that two-point fixation is the first choice for the management of ZMC fractures. Two-point fixations in zygomatic buttress and fronto zygomatic region is highly recommended for fractures with moderate displacement. The limitation of this study is, since it is a retrospective study, emphasis on the biomechanics of two-point fixation is less. So, we would like to conduct a prospective clinical trial with greater insight into biomechanics of two-point fixation.

\section{CONCLUSION}

Zygomatico maxillary complex fracture, a tetrapod fracture leads to complex facial injuries. Further these ZMC fractures leads to cosmetic and functional deformities. A well planned surgery within two weeks of injury leads to anatomic reduction and proper fixation of displaced ends. The restored bony architecture enhances soft tissue healing without formation of contracture, this is of paramount importance to prevent unsightly ectropion or lid contractures. Two-point fixations give a very stable fixation of ZMC fractures when it is done in zygomatic buttress and fronto zygomatic region. Moreover, ORIF in two points prevent the need for additional incision and miniplates and thus reduces the operating time. However, in severely displaced and communitted fractures of ZMC along with communitted fractures of zygomatic arch, it warrants additional fixation depending on the clinical situation.

\section{REFERENCES}

1. Dakir A, Muthumani T, Prabu NP, Mohan R, Maity A. One point fixation of zygomatic tripod fractures in the zygomatic buttress through Keen's intraoral approach: a review of 30 cases. J Pharm Bioallied Sci 2015;7:S238-41.

https://doi.org/10.4103/0975-7406.155934

2. Gomes PP, Passeri LA, Barbosa JR. A 5 year retrospective study of zygomatico orbital complex and zygomatic arch fractures in Sao Paulo state, Brazil. J Oral Maxillofac Surg 2006; 64:63-7 https://doi.org/10.1016/j.joms.2005.09.012

3. Ho V: Isolated bilateral fractures of zygomatic arches. Br J Oral Maxillofac Surg 1994, 32:394.

https://doi.org/10.1016/0266-4356(94)90033-7

4. Medvedev IA, Sivolapov KA: The use of titanium devices in treating fractures of the zygomatico-orbital complex. Stomatologiia (Mosk) 1993,72(1):19-23.

5. Crowe WW: Treatment of depressed fracture of the zygomatic bone. J Oral Surg 1952, 10:3.

6. Nayyar MS: Management of zygomatic complex fracture. J Coll Physicians Surg Pak 2002, 12:700-705

7. Zingg M, Laedrach K, Chen J et al (1992) Classification and treatment of zygomatic fractures: a review of 1,025 cases. J Oral Maxillofac Surg 50(8):778-790

8. Covington DS, Wainwrright DJ, Teichgraeber Jf et al (1994) Changing patterns in the epidemiology of zygoma fractures: 10 year review. J Trauma 37:243-248

9. Dingman Ro, Natvig P (1976) Surgery of facial fractures. Saunders, Philadelphia, pp 218-220

10. Rohrich RJ, Watumull D: Comparison of rigid plate versus wire fixation in the management of zygoma fractures: a long-term follow-up clinical study. Plast Reconstr Surg 1995, 96(3):570-575 https://doi.org/10.1097/00006534-199509000-00008

11. Kovacs AF, Ghahremani M (2001) Minimization of zygomatic complex fracture treatment. Int J Oral Maxillofac Surg 30(5): 380-383 
https://doi.org/10.1054/ijom.2001.0131

12. de Souza Carvalho AC, Pereira CC, Queiroz TP, Magro-Filho O. Intraoral approach to zygomatic fracture: modified technique for-keens infraorbital rim fixation. J Craniofac Surg 2012;23:537-538

https://doi.org/10.1097/SCS.0b013e3182418ea6

13. Kühnel TS, Reichert TE. Trauma of the midface. GMS Curr Top Otorhinolaryngol Head Neck Surg 2015;14:Doc06

14. Kim ST1, Go DH, Jung JH, Cha HE, Woo JH, Kang IG. Comparison of 1-point fixation with 2-point fixation in treating tripod fractures of the zygoma. J Oral Maxillofac Surg. 2011 Nov;69(11):2848-52

https://doi.org/10.1016/j.joms.2011.02.073

15. O'Hara DE, DelVecchio DA, Bartlett SP, Whitaker LA. The role of microfixation in malar fractures: A quantitative biophysical study. Plast Reconstr Surg 1996;97:345-50. https://doi.org/10.1097/00006534-199602000-00011

16. Nitsch A, Bruns A, Gruber RM, Wiese KG, Merten HA.Evaluation of the postoperative clinical results of repositioning isolated zygomatic fractures. Schweiz Monatsschr Zahnmed. 2006;116(1):43-53.

17. Ellis $E$ 3rd, Kittidumkerng W. Analysis of treatment for isolated zygomaticomaxillary complex fractures. J Oral Maxillofac Surg 1996;54:386-400 https://doi.org/10.1016/S0278-2391(96)90107-X

18. Nagasao $M$, Nagasao $T$, Imanishi $Y$, Tomita $T$, Tamaki $T$, Ogawa K. Experimental evaluation of relapse-risks in operated zygoma fractures. Auris Nasus Larynx. 2009;36(2):168-175. https://doi.org/10.1016/j.anl.2008.05.007

19. Parashar A, Sharma RK, Makkar S. Rigid fixation of zygoma fractures: A comparison of two-point and three-point fixation. Indian J Plast Surg 2007;40:18-24 https://doi.org/10.4103/0970-0358.32658

20. Gandi LN, Kattimani VS, Gupta AV, Chakravarthi VS, Meka SS. Prospective blind comparative clinical study of two point fixation of zygomatic complex fracture using wire and mini plates. Head Face Med 2012;8:7
https://doi.org/10.1186/1746-160X-8-7

21. Chuong R, Kaban LB. Fractures of the zygomatic complex. J Oral Maxillofac Surg 1986;44:283-8 https://doi.org/10.1016/0278-2391(86)90079-0

22. Nishtha Gadkari, Shilpa Bawane,Ratima Chopra, Kalyani Bhate, Deepak Kulkarni. Comparative evaluation of 2-point vs 3-point fixation in the treatment of zygomaticomaxillary complex fractures - A systematic review. J Craniomaxillofac Surg, $2019 ; 47(10): 1542-1550$ https://doi.org/10.1016/j.jcms.2019.07.009

23. Na WG, Lim H, Koh SH. Three-Dimensional Computed Tomography Analysis of Stability Following Two- and ThreePoint Fixation With Biodegradable Plates Among Patients With Zygomatic Fracture. J Craniofac Surg. 2019;30(2):478-482. https://doi.org/10.1097/SCS.0000000000005142

24. Wail Fayez Nasr ,Ezzeddin ElSheikh,Mohammad Waheed ElAnwar Ahmed Hassan Sweed. Awad Bessar, Nillie Ezzeldin. Two- versus Three-Point Internal Fixation of Displaced Zygomaticomaxillary Complex Fractures. Cranio Maxillofac Trauma Reconstruction 2018; 11(04): 256-264 https://doi.org/10.1055/s-0037-1604199

25. Sarkarat, F., Ebrahimi, S., Kahali, R., Pirhadi Rad, A., Khosravi, M., Rakhshan, V. Finite Element Simulation of Displaced ZMC Fracture After Fixation with Resorbable and Non-Resorbable One-Point Mini-Plates and Applying Normal to Severe Occlusal Loads. Trauma Monthly, 2019; 24(3): 1-7 https://doi.org/10.5812/traumamon.85586

26. Rana M, Warraich R, Tahir S, Iqbal A, von See C, Eckardt AM, et al. Surgical treatment of zygomatic bone fracture using two points fixation versus three point fixation - A randomised prospective clinical trial. Trials. 2012;13:36 https://doi.org/10.1186/1745-6215-13-36

27. Mittal G, Garg R, Sharma S, Rathi VC, Ranjan R, Khare G. Efficacy of two-point fixation in the management of zygomatic complex fractures - A prospective clinical study. Natl J Maxillofac Surg. 2019 ;10(2):223-227. doi: 10.4103/njms.NJMS_49_18. https://doi.org/10.4103/njms.NJMS_49_18

\footnotetext{
Author's Contribution

DK-Conception and design of the work; VP- design of the study and Critical revision of the article; NB-Data collection, manuscript preparation; AM- Manuscript preparation and critical revision of the article; DS- Data analysis and interpretation; DM- Reviewed the literature and final approval of the version to be published.

Work attributed to:

Department of Dentistry and Department of Ophthalmology, Indira Gandhi Medical College and Research Institute (Govt.), Puducherry-605008, India.

Orcid ID:

Dr. Devakumari- (10 https://orcid.org/0000-0001-9166-2285

Dr. Vijhayapriya- (D) https://orcid.org/0000-0001-7570-3497

Dr.Nandini Biradar- (i) https://orcid.org/0000-0003-4885-6898

Dr. Amudha- (1) https://orcid.org/0000-0002-6211-8579

Dr. Dinesh- (iD https://orcid.org/0000-0001-8583-1062

Dr. Devameena- (D) https://orcid.org/0000-0002-5418-8657

Source of Funding: None, Conflicts of Interest: None.
} 